\section{Abordagem Semiótica de Gêneros}

Multimidiáticos: Uma Perspectiva para

o Ensino Aprendizagem de Língua

Portuguesa na Era Digital

A Semiotic Approach of Multimidiatic Genres: A Perspective to the

Teaching - Learning of Portuguese in the Digital Era

Julio Neves Pereira*

RESUMO: As novas práticas sociais trazem como implicação que a presença constante do texto multimidiático como forma de comunicação na vida das pessoas, potencializada pelas tecnologias digitais, impóes um novo modo de ser e de viver. Em nossas pesquisas que vimos realizando, os resultados vêm mostrando a necessidade de que o ensino da leitura e da escrita do texto multimidiático passe a ser objeto de ensino nas aulas de língua portuguesa. Portanto, pretendese, aqui, discutir e refletir sobre as possíveis abordagens semióticas do texto multimidiático. Os pressupostos teóricos são (1) a diversidade dos gêneros atrela-se à situaçáo, à posição social e às relaçóes pessoais de reciprocidade entre os participantes da comunicação (2) $\mathrm{O}$ trato com a linguagem no âmbito escolar requer uma pedagogia dos multiletramentos (3) A multimodalidade presente em texto dessa natureza compreende que os modos semióticos constitutivos se organizam a partir de relações semânticas (4) Toda semiótica é semiótica multimídia e todo letramento é letramento multimidiático (5) O ensino do texto multimidiático deve se dar por meio de uma metalinguagem facilitadora da aprendizagem (Unsworth). Desse modo, neste trabalho, apresentam-se perspectivas metodológicas para o ensino-aprendizagem da leitura e da produção do texto em linguagem multimidiática.

PALAVRAS-CHAVE: Linguagem multimidiática; Semiótica social; Multiletramentos; Metalinguagem; Ensino-aprendizagem.

ABSTRACT: The new social practices imply that the constant presence of the text multimedia as a form of communication in people's lives, enhanced by digital technologies, imposes a new way of being and living. In our research that we have been carrying out, the results have shown the need for the teaching of reading and writing multimedia text to become the object of teaching in Portuguese language classes. Therefore, it is intended here to discuss and reflect on the possible semiotic approaches of the multimedia text. The theoretical assumptions are: (1) The diversity of genres is linked to the situation, social position and personal relationships of reciprocity between

\section{Linguagęm Foco}

Revista do Programa de Pós-Graduação em Linguística Aplicada da UECE

Universidade Federal da Bahia (UFBA), Profletras, Instituto De Letras; Professor Associado; julio.pereira@ufba.br.
Distribuído sob

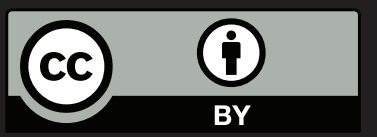


participants in the communication (2) Dealing with language in the school environment requires a multi-element pedagogy (3) The multimodality present in such a text comprises that the constitutive semiotic modes are organized based on semantic relations (4) All semiotics are multimedia semiotics and all literacy is multimedia literacy (5) The teaching of the multimedia text must take place through a metalanguage that facilitates learning Thus, in this work, methodological perspectives are presented for the teaching-learning of reading and text production in multimedia language.

KEYWORDS: Contract of Media Communication; Nova Escola Magazine; Reading Teach.

\section{INTRODUÇÃO}

Hoje, há uma profusão de textos resultantes da combinação de modos semióticos distintos circulando na vida das pessoas, tanto por meio do suporte tradicional, quanto, e sobretudo, por meio do suporte tela. Imagens, palavras, sons vêm sendo utilizados em combinatórias que visam à significação. O que nos faz pensar que a interação desses modos é constitutiva da arquitetura textual-discursiva da contemporaneidade. Portanto, tais textos se constituem por aquilo que já se denomina de linguagem multimidiática (DAILY, 2010). E isso tem implicaçóes. Citamos duas.

1. A linguagem multimidiática da tela (também do impresso) que é capaz de construir significados complexos, se transformou no vernáculo corrente (DALEY, 2010, p.10).

2. As tecnologias nos afastam da era da escrita forçando-nos a sermos autores multimidiáticos autoria multimidiática - (LEMKE, 2010, p. 456).

Nessa nova conformação comunicacional, a presença da imagem é constante. Ele está presente praticamente em todos os textos multimidiáticos, principalmente em interação com a palavra. E nisso reside o problema de que nem mesmo conseguimos ensinar a leitura crítica da imagem, como sistema semiótico, temos agora que proceder sua leitura em articulação complexa com outros modos. Essa é uma questão que já demanda respostas.

Mas, nesse contexto, nossa indagação, hoje, circunscreve-se a saber como se dá a relação interacional verbo-imagética no processo de significação, e mais especificamente no campo do ensino-aprendizagem, isto é, como ensinar e como aprender a ler criticamente e, ao mesmo tempo, ser autor crítico ao utilizar a linguagem multimidiática, o vernáculo dos dias de hoje.

Nossas pesquisas que vêm sendo desenvolvidas em escolas soteropolitanas periféricas têm nos mostrados como os alunos não têm sido preparados para serem leitores críticos de textos multimodais, tanto no suporte papel, quanto no suporte tela. Nossas constataçóes vêm sinalizando que:

a. No contexto escolar, quando o texto apresenta imagem e palavra, o leitor (aprendizes da língua portuguesa) tende a desconsiderar a parte imagética como produtora de sentido, dando relevância 
quase absoluta para as informaçóes veiculadas pelo sistema verbal. Isso indica que a imagem não é considerada parte integrante do texto. Não se tem observado processo de leitura multissemiótica.

b. Quando instados a fazerem relaçôes entre os modos, tem-se observado dificuldades dos participantes em estabelecer relaçóes semânticas entre os sistemas. Não havia clareza por parte deles quanto à necessidade da presença da imagem no "texto".

c. As informaçôes da imagem não são relevadas, conscientemente, na produção de sentidos, a favor das que são carreadas pelo enunciado linguístico. A exceção se dá quando a imagem é a que carreia a informaçáo mais importante ou a que completa algum sentido expresso pelo enunciado verbal.

d. A relação entre os modos era mais bem entendida quando a leitura era realizada em conjunto em um processo de problematização pesquisador/ participante.

e. Quando utilizados textos em que havia imagens que carreavam determinadas informaçóes ideologicamente marcadas, os sentidos produzidos não eram interpretados nem problematizados pelo grupo de participantes. Essa constatação nos faz pensar que a leitura multimidiática é realizada como se fosse um texto neutro. Questôes de fundo são relevadas, tais como a seleção dos participantes, suas características físicas, suas vestes, gestos, o ambiente em que se encontram etc.

f. Outra constatação, mais que evidente, é que o texto multimidiático não é considerado importante para o desenvolvimento das capacidades de leitura e de produção textual, porque existe a crença bastante arraigada de que o aluno deve aprender escrever e ler, ou seja, ter domínio do modo verbal escrito, como se isso bastasse nos dias de hoje.

Essas constataçôes obrigaram-nos questionar:

1. É necessário ensinar, aprender a ser autor multimidiático?

2. É importante trabalhar nas escolas gêneros multimidiáticos? É necessário ensinar, aprender a ser leitor desse texto?

3. Se sim, como fazê-lo? Por onde começar?

Sáo questóes que emergem desse novo contexto e nos coloca, a meu ver, professoras, professores e pesquisadoras e pesquisadores, em uma posição responsiva.

Nesse sentido, se levarmos em conta que:

1. Neste século XXI, são/serão consideradas letradas, aquelas pessoas que aprenderem a ler e a escrever a linguagem multimidiática da tela de modo crítico (DAILY, 2010);

2. e por nós náo temos tido a preocupação de ensinar nossos alunos a combinar, com eficiência 
comunicativa e crítica, desenhos e diagramas e escrita, imagens fotográficas de arquivos, vídeos, efeitos sonoros, voz em áudio, música, animação etc. (LEMKE, 2010);

3. e que cada vez mais cresce a circulação de textos que são lidos e compartilhados acriticamente por meio das redes sociais, alimentando preconceitos, reforçando estereótipos,

Parece-nos que a resposta é sim, taxativamente. Temos que ter em nosso currículo, programa, no plano de aula previsto o trabalho com os gêneros multimidiáticos, em que metodologias específicas sejam desenvolvidas para facilitar e solidificar o tratamento interpretativo e de produção, no processo de ensinoaprendizagem. Para tanto, tomando de empréstimo a ideia de Lemke (2010), é necessária a compreensão e o domínio de como cada modo semiótico funciona isoladamente no processo de significação e como os modos funcionam em interação para produzir sentido, porque diz Lemke (2010)

\begin{abstract}
devemos ajudar os alunos a compreenderem exatamente como ler o texto de forma diferente e interpretar a imagem de forma diferente, em função da presença um do outro. Nós precisamos até mesmo compreender como é que sabemos qual enunciado verbal é relevante para a interpretação de qual imagem e vice-versa. Tudo isto requer, ao menos para professores e especialistas da mídia, uma compreensão útil de semiótica multimidiática. (LEMKE, 2010, p. 463)
\end{abstract}

Mas essa ajuda defendida pelo teórico, encontra barreiras, que, embora não sejam intransponíveis, trazem retardo para a efetivação da prática e da reflexão sobre nossa problemática. Uma destas barreiras é que a escola, embora faça parte da sociedade, dela se afasta quando se trata de trazer para dentro dela os novos modos de comunicação, que nela entram sob a forma de currículo informal.

Nos portôes da escola, no pátio, nos banheiros, e até mesmo na sala de aula, discretamente, ou em muita evidência, lá estão os jovens e as jovens escrevendo, lendo, compartilhando, jogando em suas redes sociais. E a professora e o professor, em suas aulas, utilizando as tecnologias de sempre, passando os conteúdos de sempre e do mesmo modo de sempre.

Outra barreira, que se observa, é a que diz respeito à crença de que textos multimidiáticos, ou antes, o uso da linguagem multimidiática, não se configuram como objeto de ensino-aprendizagem, sobretudo os que advém das tecnologias digitais.

Temos também a barreira infraestrutural, visto que não há, sistematicamente, condiçôes de na escola se trabalhar com o aparato tecnológico que permita o professor levar o aluno a combinar modos semióticos. Vinculada a essa barreira, quando a escola possui os recursos tecnológicos, a questáo se volta para a formaçáo docente que náo permite à professora nem ao professor lidar com tais recursos, seja para operar a ferramenta, seja para lidar pedagogicamente, didaticamente com ela em suas aulas. Os que conseguem, o fazem menos por sua formação formal, e mais pela sua formação fora dos muros da universidade.

De acordo com o que vimos depreendendo em nossa pesquisa em andamento, muitos docentes usam os notebooks, computadores e /ou tablets que a escola possui para pesquisa própria, fazer o aluno pesquisar, mas não se observa nenhuma atividade sistemática por meio da qual se coloca o aluno para ler ou produzir textos vários, sobretudo os multimidiáticos como uma prática continua que possibilitasse-nos 
pensar que a linguagem multimidiática estivesse sendo incorporada efetivamente naquele meio escolar.

A nosso ver, isso é consequência da formação inicial e continuada, que de alguma forma cristalizou a crença de que em aula de língua portuguesa não se utilizam outros recursos tecnológicos, e que o texto é aquele que tem predominância ou exclusividade da letra no papel.

De acordo com Guimarães (2010), ao longo da vida, concepções e crenças vão se constituindo na vida das pessoas por três modos: processo de aprendizagem não orientado por meio da observação, participação e imitação individuais (Inculturação); pelo processo de aprendizagem intencional e orientado conforme normas culturais vigentes (Educação); e pelo processo de ensino propriamente dito que se dá em instituiçóes específicas, como a escola (Instrução).

Segundo este autor, baseado em Brown e Cooney (1982, apud GUIMARÁES, 2006), a "Inculturação" propicia a construção de crenças em todas as fases escolares a que está sujeito o futuro professor. Sua vivência com as matérias disciplinares, com os ambientes escolares e com os diferentes professores vão dando forma ao sistema de crença. E não temos proporcionado, ainda, um ambiente escolar em que tal vivência seja sistemática no processo de iniciação à docência.

No processo "Educação", ao contrário, forma-se este sujeito adequando-o ou buscando adequálo às normas da cultura escolar. Nesse processo, também age a interação entre os atores escolares. Em se pensando na presença tecnológica na construção identitária e formativa do docente em iniciação, também não temos propiciado isso, visto que ainda os textos multimidiáticos não fazem parte da cultura escolar (currículo) nem de seus agentes.

Referente ao processo "Instrução", por final, que consiste no processo de formação continuada do professor por meio de instituiçóes específicas, também estamos engatinhando, porque muitos programas de formação continuada ainda não incorporaram em sua matriz curricular a necessidade de se tratar destas questóes de modo sistêmico e efetivo.

Jewitt (2008) explica que nesse novo contexto os modos da comunicação estão mudando de maneira profunda, fazendo-se sentir em todos os setores da vida, seja no âmbito escolar, seja no do cotidiano das pessoas. A estudiosa aponta para o fato de que não se pode pensar o letramento descolado de todas essas transformações social, tecnológica e econômica, já que, como constatam Kress, G.; Van Leeuwen, T. (2001, p.1), os dois movimentos do século: domínio da imagem e o consequente declínio da escrita, e a tela passando a ser o novo suporte do livro revolucionam a toque de caixa os usos, os efeitos do letramento e de meios associados para representar e comunicar em todos os níveis e domínios .

É nesse cenário que vimos propor um caminho, que já está sendo trilhado na academia. Defendemos que o professor, a professora para mudar sua crença precisa entrar em contato com cabedal teórico e prático, norteado por uma pedagogia que os instrumentalize a lidar com a linguagem multimidiática a fim de saber ler e produzir gêneros discursivos multimidiáticos, e os posicione, o professor, a professora, criticamente diante da diversidade cultural e tecnológica.

Temos tido vários estudos que buscam esse intento de que falo aqui. Mas tenho visto que no letramento multimidiático, a compreensão das relações que se estabelecem entre os modos precisam estar mais bem claras e solidificadas de modo mais consciente.

Para nós, a Semiótica social, que tem em sua base, pressupostos da Gramática Visual e da Gramática

\begin{tabular}{c|c|c|c}
\hline Revista Linguagem em Foco & Fortaleza, CE & v. 11 n. 2 & ISSN 2674-8266 \\
\hline
\end{tabular}


$\overline{\text { Funcional tem possibilidades de dar respostas didáticas eficazes quando operada a partir da perspectiva da }}$ Pedagogia dos Multiletramentos, desenvolvida por Kalantzis e Cope (2000).

Considero que o autor multimidiático e seu leitor precisam, na apreensão do gênero multimidiático, e por consequência na manipulação eficiente da linguagem multimidiática, observar o gênero a partir das metafunçóes sociais (universais semióticos). É importante que o professor e o aluno consigam interagir com o texto a partir dessas categorias, que embora estejam apresentas isoladamente, estáo presentes no texto simultaneamente.

Para a abordagem de como no texto imagem e léxico estão interagindo na produção de sentido, partimos das categorias lógico-semânticas defendida por Unshworth (2006), que baseado em outras contribuições, propóe que na parte de descrição da representação dos significado ideacional se trabalhe com as categorias EXPANSÃO E PROJEÇÃO e suas subcategorias. Na descrição do universal semiótico ORIENTACIONAL, que se trabalhe com o sistema de modalização e sistema de Avaliatividade; e na parte ORGANIZACIONAL, que se trabalhem os tipos de relação coesiva que se dá entre os modos semióticos em relaçáo a qualidade da informação (dado/novo). 


\section{Quadro 1}

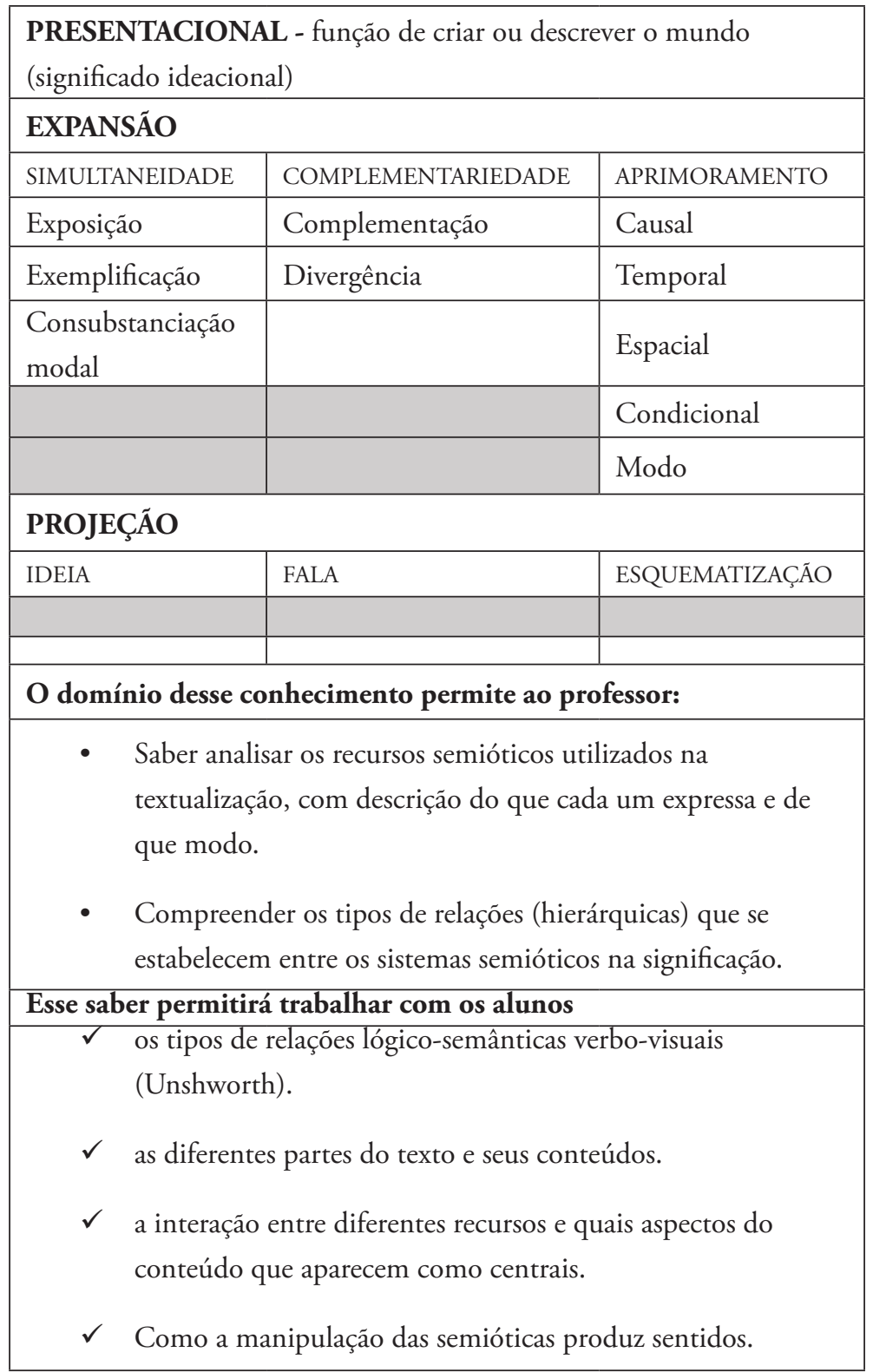

Fonte: elaborado pelo autor 


\section{Quadro 2}

\begin{tabular}{|c|c|c|}
\hline \multicolumn{3}{|c|}{$\begin{array}{l}\text { ORIENTACIONAL - função de tomar partido em relação aos } \\
\text { conteúdos ou a suas audiências }\end{array}$} \\
\hline \multicolumn{2}{|c|}{ Sistema de modo e modalidade } & $\begin{array}{l}\text { Sistema } \\
\text { Avaliatividade }\end{array}$ \\
\hline $\begin{array}{c}\text { Contato } \\
\underline{\text { Demanda ou }} \\
\underline{\text { oferta }}\end{array}$ & $\begin{array}{c}\text { Distanciamento social } \\
\text { Enquadramento }\end{array}$ & $\begin{array}{l}\text { Atitude: sentimentos } \\
\text { e sua construção, } \\
\text { julgamento }\end{array}$ \\
\hline Relação entre & $\begin{array}{l}\text { Relação social entre os } \\
\text { participantes }\end{array}$ & $\begin{array}{l}\text { Engajamento: posição } \\
\text { dos participantes na } \\
\text { interação }\end{array}$ \\
\hline $\begin{array}{c}\text { os participantes } \\
\text { pelo } \\
\text { direcionamento } \\
\text { do olhar }\end{array}$ & (proximidade/afastamento) & $\begin{array}{l}\text { Gradação: } \\
\text { intensidade/mitigação } \\
\text { dos significados }\end{array}$ \\
\hline \multicolumn{3}{|c|}{ O domínio desse conhecimento permite ao professor: } \\
\hline $\begin{array}{r}\text { interpes } \\
\text { entre o } \\
\text { relação } \\
\text { - } \quad \text { Compr } \\
\text { (de cul }\end{array}$ & $\begin{array}{l}\text { alisar e descrever os recursos } \\
\text { ais combinados para construir } \\
\text { participantes e os valores ideo } \\
\text { ender as relações entre os sign } \\
\text { tra e de situação) em que ocor } \\
\text { e os sentidos são resultantes d } \\
\text { emióticos sob influências hist } \\
\text { cas. }\end{array}$ & $\begin{array}{l}\text { rbais e visuais } \\
\text { natureza de relaçóes } \\
\text { gicos projetos na } \\
\text { icados e os contextos } \\
\text { s combinaçóes dos } \\
\text { icas, sociais, políticas e }\end{array}$ \\
\hline \multicolumn{3}{|c|}{ Esse saber permitirá trabalhar com os alunos: } \\
\hline $\begin{array}{l}\square \quad \text { a organ } \\
\text { contex }\end{array}$ & $\begin{array}{l}\text { zação das estruturas semiótica } \\
\text { s de produção. }\end{array}$ & e a significação aos \\
\hline $\begin{array}{l}\square \quad \text { Os mo } \\
\text { discurs }\end{array}$ & $\begin{array}{l}\text { os de relação entre os interloc } \\
\text { a projetada pela combinatória }\end{array}$ & $\begin{array}{l}\text { ores e sua posição } \\
\text { entre as semióticas. }\end{array}$ \\
\hline $\begin{array}{l}\text { Escolh } \\
\text { engajar }\end{array}$ & $\begin{array}{l}\text { lexical e imagética que materi } \\
\text { entos e gradação materializad }\end{array}$ & $\begin{array}{l}\text { izam as atitudes, os } \\
\text { no texto. }\end{array}$ \\
\hline
\end{tabular}

Fonte: elaborado pelo autor 


\section{Quadro 3}

ORGANIZACIONAL - função de ligar as partes ao todo (significado composicional)

- $\quad$ Relação espacial entre imagem e o enunciado linguístico.

- Saliência ou não de partes da imagem pelo tamanho e a posiçáo do conjunto de palavras e localização da imagem.

- As palavras podem enfatizar diferentes aspectos da imagem.

- A imagem às vezes atravessa o léxico e a gramática do enunciado para criar humor ou ritmo visual.
- Arranjo visual da imagem e da escrita pode: indicar no construto narrativo, intensidade de emoção, alinhamento do espectador com o ponto de vista de um personagem.

- Enquadramentos podem ser cruciais na interpretação dos significados em jogo e no estabelecimento da posição avaliativa do escritor em relação aos significados (Macken-Horarik, 2003b; Unsworth, 2006a).

\section{O domínio desse conhecimento permite ao professor:}

- Manipular e remanipular os modos semióticos de acordo com as relaçóes que se quer estabelecer entre os significados e os contextos (de cultura e de situação).

- Ter a espacialidade como recurso de produção de sentido entre as semióticas.

- Ter que tamanho das letras em relação as imagens produz sentido.

- Saber que (re)combinaçóes geram pontos de vista diferentes.

Esse saber permitirá trabalhar com os alunos:

Prática de sampleagem e remixagens, não de modo intuitivo, apenas, mas de modo intencional, explorando caracteres das letras em relação às imagens e vice-versa, as relações espaciais entre as semióticas (aproximação/distanciamento; esquerda/direita; alto/baixo), sabendo estabelecer relaçóes lógico-semânticas, decidindo quando e qual semiótica expandirá o sentido uma da outra.

Organização das materialidades se preocupando com a distribuição do valor da informação ou da ênfase relativa entre os elementos do texto e da imagem (tema/ rema).

Fonte: elaborado pelo autor 


\section{CONSIDERAÇÓES FINAIS}

Assim, a questão dos letramentos multimidiáticos está integralmente ligada às análises descritivas reais dos sistemas de significação, norteadas por uma pedagogia dos multiletramentos. Aspectos práticos da sala de aula vem mostrando como o conhecimento dos sistemas de significaçáo e como saber operálos didaticamente criam as condiçóes para os professores e alunos passarem a lidar criticamente com a linguagem multimidiática, acarretando, acreditamos, mudança de crença e impelindo a reorientação do currículo escolar, não de cima para baixo, mas da necessidade da professora/o em se trabalhar nessa perspectiva.

Com esse cabedal sendo dominado pela professora e pelo professor, e trabalhado com o aluno, com a aluna, acreditamos, juntamente com Unsworth (2006), que tanto o professor quanto o aluno terão instrumental importante que lhes permitirá interpretar, e ser autor de gêneros multimidiáticos com a criticidade que os tempos de hoje exigem dos sujeitos, e por extensão da escola. Mas, entendemos que essa mudança, que é necessária para que possamos agir mais efetivamente na problemática que trouxemos aqui, não se dá de um dia para o outro, nem de forma fácil, pois vai além do desejo de o professor mudar, enseja um trabalho estruturante capaz de ajudá-lo nesse caminho de vir a se tornar o sujeito da transformação juntamente com seu aprendiz.

\section{REFERÊNCIAS}

COPE, B.; KALANTZIS, M. (Org.). Multiliteracies: Literacy Learning and the Design of Social Futures, Routledge, London, 2000.

GUIMARÃES, H. M. Concepçôes, crenças e conhecimento - afinidades e distinçôes essenciais. Quadrante v. XIX, n.o 2, p. 81-102. 2006. Disponível em: http://hdl.handle.net/10451/11019. Acesso em jun 2018.

JEWITT, C. Multimodality and Literacy in School Classrooms. Review of research in Education. v. 32, p. 241. 2008. Disponível em: https://journals.sagepub.com/doi/full/10.3102/0091732x07310586 Acesso: Ago. 2018.

KRESS, G.; VAN LEEUWEN, T. Multimodal Discourse: The modes and media of contemporary communication. New York: Oxford University Press, 2001.

LEMKE, J. Letramento metamidiático: transformando significados e mídias. Trab. Ling. Aplic., Campinas, 49(2): 455-479, Jul./Dez. 2010.

MAGALHÃES, C. M. \& ARAÚJO, W. M. de Os professores e o medo da mídia. Inter-Ação, Goiânia, v. 39, n. 3, p. 575-592, set./dez. 2014.

PEREIRA, J. N. A textualização multimodal do texto didático: implicações teórico-metodológicas. In: PEREIRA, J. N. e SILVA, S. B. B. (Org.) Lingua Portuguesa e Literatura no livro didático: desafios e perspectivas. Campinas, S.P.: Pontes Editores, 2018.

PEREIRA, J. N. Gêneros multissemióticos: questão de multiletramento. In: FREITAS, J. H. \& ASSUMPÇÃO. S. S. (Org.) Redes de Aprendizagem entre a escola e a universidade. Salvador, EDUFBA, 
2019.

SILVA, S. B. B. \& PEREIRA, J. N.(Org.). Lingua Portuguesa e literatura no livro didático: desafios e Perspectivas. Campina, SP: Pontes, 2018.

KRESS, G.; VAN LEEUWEN, T. Multimodal Discourse: The modes and media of contemporary communication. New York: Oxford University Press, 2001.

UNSWORTH, L. Towards a metalanguage for multiliteracies education: Describing the meaningmaking resources of language-image interaction. English Teaching: Practice and Critique May 2006, v. 5, n. 1. Disponível em: http://education.waikato.ac.nz/research/files/etpc/2006v5n1art4.pdf pp. 55-76. Acesso maio 2018. 